Insight, part of a Special Feature on Education and Differential Vulnerability to Natural Disasters

\title{
Vulnerability to Weather Disasters: the Choice of Coping Strategies in Rural Uganda
}

\author{
$\underline{\text { Jennifer F. Helgeson }}^{1,2}$, Simon Dietz $^{1,2}$ and Stefan Hochrainer-Stigler $^{3}$
}

\begin{abstract}
When a natural disaster hits, the affected households try to cope with its impacts. A variety of coping strategies, from reducing current consumption to disposing of productive assets, may be employed. The latter strategies are especially worrisome because they may reduce the capacity of the household to generate income in the future, possibly leading to chronic poverty. We used the results of a household survey in rural Uganda to ask, first, what coping strategies would tend to be employed in the event of a weather disaster, second, given that multiple strategies can be chosen, in what combinations would they tend to be employed, and, third, given that asset-liquidation strategies can be particularly harmful for the future income prospects of households, what determines their uptake? Our survey is one of the largest of its kind, containing over 3000 observations garnered by local workers using smartphone technology. We found that in this rural sample, by far, the most frequently reported choice would be to sell livestock. This is rather striking because asset-based theories would predict more reliance on strategies like eating and spending less today, which avoid disposal of productive assets. It may well be that livestock is held as a form of liquid savings to, among other things, help bounce back from a weather disaster. Although, we did find that other strategies that might undermine future prospects were avoided, notably selling land or the home and disrupting the children's education. Our econometric analysis revealed a fairly rich set of determinants of different subsets of coping strategies. Perhaps most notably, households with a more educated head are much less likely to choose coping strategies involving taking their own children out of education.
\end{abstract}

Key Words: coping strategies; covariate risk; education; extreme weather; poverty trap; small-scale farming; Uganda; vulnerability

\section{INTRODUCTION}

Extreme weather events often have severe impacts on lives and livelihoods in the developing world, and climate change is predicted, with varying degrees of confidence, to increase the frequency and intensity of extreme weather in the future (IPCC 2007). It is therefore of great interest to investigate how vulnerability to extreme weather can be reduced.

One aspect of vulnerability is the way in which households cope in the aftermath of a weather disaster. A variety of coping strategies may be employed, from reducing current consumption, for example, reducing expenditure and food intake, to disinvestment, for example, disposing of assets such as land and livestock, and also, reducing investment in educating children. Disinvestment strategies are especially worrisome because by eroding the household's capital stock now and in the future, they erode the capacity of the household to generate income, which may eventually lead to chronic poverty.

We used the results of a household survey in rural Uganda to inquire into the nature of coping strategies used after an extreme weather event and their drivers. Our survey is one of the largest of its kind, containing over 3000 observations garnered by local workers using smartphone technology. As part of a much larger survey, we constructed a hypothetical scenario in which our respondents were exposed to a large drought/flood, which rendered them unable to rely on formal support from the market or state, or from local remittances. We asked them to state which coping strategies they would expect to employ in this scenario.

This enabled us to investigate three things. First, we investigated the nature of the coping strategies most frequently employed, i.e., do respondents turn most often to strategies that reduce current consumption but avoid disinvestment? Or are they in fact more likely to disinvest, and in what? Second, given that multiple strategies can be chosen, we investigated what combinations would tend to be employed. This gave us further insight into the propensity of surveyed households to disinvest, i.e., are disinvestment strategies chosen alongside consumption-reduction strategies, or in isolation? Finally, using the wealth of socioeconomic information that we collected in other parts of the survey, we investigated what determined the uptake of disinvestment strategies that could be particularly harmful for the future income prospects of households.

\section{NATURAL DISASTERS, VULNERABILITY, AND COPING STRATEGIES}

The ultimate impact of a natural disaster on a household depends on the household's vulnerability to its effects. In the literature on vulnerability, it is often conceptualized as a function of three elements, i.e., exposure, sensitivity, and

\footnotetext{
${ }^{1}$ London School of Economics and Political Science, Department of Geography and Environment, ${ }^{2}$ The Grantham Research Institute on Climate Change and the Environment, ${ }^{3}$ IIASA - International Institute for Applied Systems Analysis
} 
adaptive capacity (Adger and Winkels 2007). Depending on the unit of analysis, e.g., the individual, the nation, etc., these elements can take on somewhat different meanings, although the basic scope of the framework remains the same.

For our purposes, exposure depends on the physical characteristics of the natural hazard, including its magnitude and the frequency of occurrence. This makes sense when the unit of analysis is a particular household in space and time, but otherwise exposure clearly also depends on who lives where, the value of their assets, and so on. Sensitivity, in the household context, denotes the extent to which it can absorb the impacts of the disaster without suffering long-term harm. Adaptive capacity represents the ability of the household to evolve to cope with a changing exposure to natural disasters. Therefore, when one takes a snapshot of household circumstances at a particular point in time, adaptive capacity reduces sensitivity, and it is convenient to look at the two together.

In terms of exposure, it is well known that Africa, especially sub-Saharan Africa, experiences a large number of droughts and floods, and although there is considerable uncertainty, there is some evidence from predictive modeling studies to suggest that extreme weather will become more frequent in the future because of anthropogenic climate change (Boko et al. 2007, IPCC 2007). In terms of sensitivity and adaptive capacity, it is also widely understood that the impacts of natural disasters are disproportionately large in the developing world, especially in Africa, most especially rural Africa. Our interest, however, is more fine grained and concerns differential vulnerability to extreme weather within the rural developing world, in particular between households living in a broadly similar socioeconomic context, i.e., rural Uganda.

One of the proximate determinants of vulnerability is the choice of strategies households make to manage natural disaster risks. Strategies for managing natural disaster risks are usually divided into ex ante and ex post (Mechler 2004). Our interest is in ex post coping strategies. As with ex ante strategies, these can be grouped into formal, i.e., market-based or publicly provided, and informal, i.e., self-organized on the individual or household/group levels.

When coping with the aftermath of a natural disaster, a household faces a form of portfolio-choice problem. The portfolio could include everything from reducing spending and eating less, through begging and borrowing, migration, selling physical assets, taking children out of school either to work or live elsewhere, to relying on state-based disaster relief, remittances, or insurance payouts.

Rural households in developing countries, however, have in most cases a very limited portfolio, including reducing current spending on food and other items, if possible given the constraints set by subsistence, and disposing of assets such as livestock and land. One of the reasons for this limited choice set is the unavailability of formal strategies because of weak public services and a lack of penetration of market-based instruments because of, for example, a lack of institutions to provide finance or a lack of collateral. Another reason for the limited choice set is the nature of the disaster, i.e., in many cases, the disaster affects the majority of individuals simultaneously, a covariate risk, and therefore informal insurance structures, e.g., family and social networks, do not provide effective relief either.

This unfortunate combination of circumstances can mean that, in the event of a covariate natural hazard, the poorest households may resort to coping strategies tipping them toward chronic poverty, sometimes conceptualized as a poverty trap (Barrett et al. 2006). A poverty trap exists if a household's assets fall to a level below which income growth cannot be supported, and this approach is used to explain low growth paths after disaster events (Carter and Barrett 2006). A lack of productive assets is seen as the most significant driver of the poor falling into vicious circles of extreme poverty (Carter et al. 2007). Therefore, in the context of coping with natural disasters, the key issue is whether a household will need to liquidate productive assets or equivalently reduce the rate of investment in assets, providing it with a means of survival in the short run, but eroding its capacity to earn income and for livelihoods in the longer run.

We are interested in what coping strategies households would employ in the aftermath of a (covariate) natural disaster, and what determines the choice of coping strategies involving various kinds of disinvestment. Within the subset of coping strategies that are likely to damage long-term prospects by disinvesting, we include a focus on strategies involving the disruption and curtailment of children's education. Theories of growth recognize the increasing role of human-capital formation in the development process, in particular a shift in the course of development from demand for skills acquired on the job to skills acquired through formal education (Galor 2011).

It may be assumed that the rational approach to coping with a natural disaster for a household is to first choose those coping strategies that do not erode the household's productive assets now and their accumulation for the future, and resorting to disinvestment only when absolutely necessary. Corbett's (1988) well-known review of the literature on coping with famine interprets various case studies as saying exactly this (see also Ravallion and Chen 1997, Ellis and Mdoe 2003), and it is consistent with Banerjee's (2000) explanation of poverty as vulnerability.

Recent empirical literature yields contrasting and nuanced findings. There is some specific evidence that coping strategies that reduce human-capital investment by sending children to work rather than to school are avoided for as long 
as possible (Flug et al. 1998), and this is consistent with the idea that they fall low in the priority-ordering of strategies. However, other studies find that this does not hold true for the poorest households, for whom the immediacy of coping outweighs future returns to human-capital investment (Jacoby and Skoufias 1997, Duryea 1998, Skoufias and Parker 2002). The notion clearly emerges that coping-strategy choice depends on household circumstances.

Similarly, there is mixed evidence on how we should consider the sale of livestock as a coping strategy. Some studies find that selling livestock is one of the first coping strategies households turn to because livestock are held as a form of liquid savings for, among other things, coping with natural disasters (Dercon 1998, Kinsey et al. 1998). Other studies find that the sale of livestock plays a marginal role in coping with extreme weather, or is only employed if households do not have access to other methods of risk-sharing, such as formal credit (Fafchamps and Gavian 1996, Kazianga and Udry 2006), which is actually rather uncommon in many rural parts of sub-Saharan Africa. Two factors that may bear upon the reliance on selling livestock are, first, the extent to which households need to augment cash income as opposed to food consumption, and second, the type of natural disaster, i.e., sale of livestock makes more sense when the environmental shock is a drought or flood because the shock reduces available grazing land and some or all of the livestock could be lost anyway.

In the process of looking at what coping strategies are employed, these studies also offered up clues about the determinants of choice. Unsurprisingly, household income/ wealth is seen to play quite a strong role, and this is corroborated by other literature on differential vulnerability (Wisner et al. 2004). Other studies, however, stress that social and demographic factors such as ethnicity, gender, age, and seniority within the community may also be at play (Anderson and Woodrow 1998, Eade 1998). Further clues are provided by the literature on climate vulnerability at the global level, which has stressed the contribution to vulnerability from low incomes, a lack of livelihood diversification, a lack of infrastructure, including infrastructure that provides resilience to extreme weather, such as water storage and flood defense, limited access to credit and insurance, and weak social safety nets (Stern 2007). In the context of credit and social safety nets, one way to cope that may still be operable after a covariate natural disaster is through remittances. As mobile banking has taken hold throughout sub-Saharan Africa, remittances have surged (Blumenstock et al. 2011, Jack and Suri 2011).

We contribute to the literature on coping strategies by reporting relevant results from one of the largest surveys of household disaster-risk management in the developing world, implemented using novel smartphone technology with the help of a network of local community knowledge workers. We provide new evidence on which coping strategies are used most frequently. In particular, we add to the literature pointing to the importance of selling livestock as a means of recovering from a disaster, but we also focus on how often households fall back on disinvestment in the education of children, and the associated causes. The effect of natural disasters on household investment in children's education has not been studied extensively to date.

\section{SURVEY DESIGN}

The survey, on which our results are based, was conducted in two districts of Uganda. Oyam district is in northern Uganda, bordering the recently war-torn Gulu region. The town of Oyam lies at $02^{\circ} 14^{\prime} 04^{\prime \prime} \mathrm{N}$ and $32^{\circ} 23^{\prime} 06^{\prime \prime} \mathrm{E}$, at an altitude of $900 \mathrm{~m}$. The second district is Kapchorwa, in the east of Uganda, bordering Kenya and encompassing Mt. Elgon. The town of Kapchorwa lies at $01^{\circ} 24^{\prime} 00^{\prime \prime} \mathrm{N}$ and $34^{\circ} 27^{\prime} 00^{\prime \prime} \mathrm{E}$. The two regions were chosen to capture intracountry variation in disposable income, as well as geographic location. Nevertheless, the economies of both regions are based primarily on subsistence agriculture. Figure 1 maps the study areas in the context of Uganda.

Fig. 1. Study areas: Oyam $\left(02^{\circ} 14^{\prime} 04^{\prime \prime} \mathrm{N}\right.$ and $\left.32^{\circ} 23^{\prime} 06^{\prime \prime E}\right)$ and Kapchurwa $\left(01^{\circ} 24^{\prime} 00^{\prime \prime} \mathrm{N}\right.$ and $\left.34^{\circ} 27^{\prime} 00^{\prime \prime} \mathrm{E}\right)$.

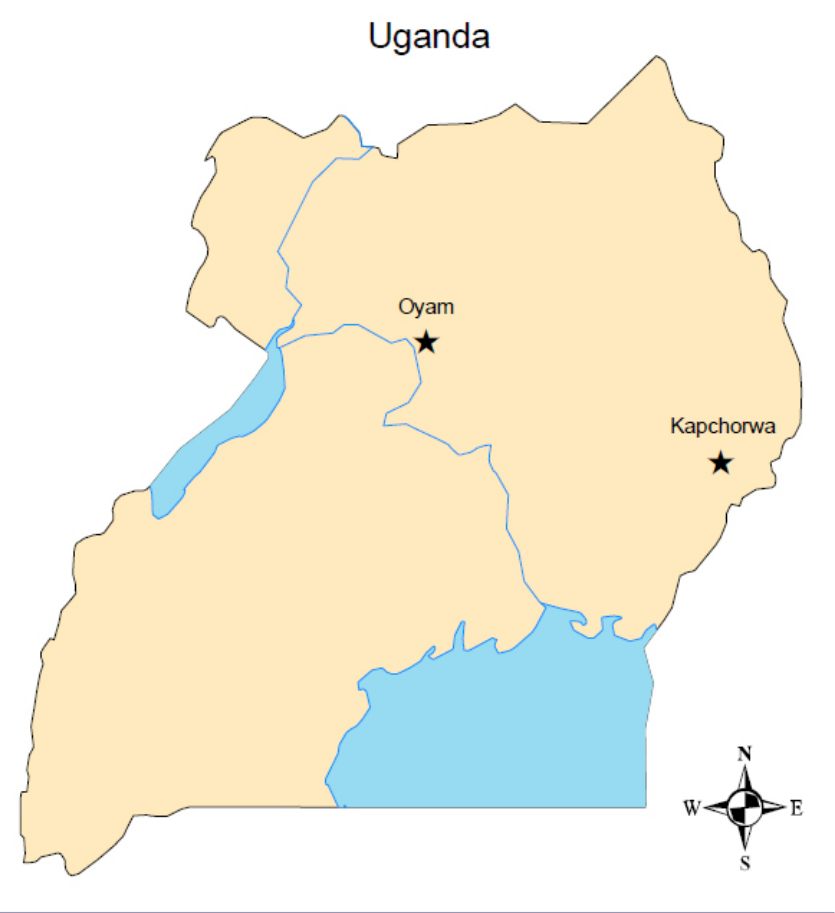

Farming methods in these two areas are traditional, not encompassing much technological advancement. Only $1 \%$ of the households we sampled own a borehole, for example, and mechanized ploughs and active irrigation are seldom used. 
Most farming families in our sample have a source of secondary income, including small shop ownership, participation as an educator in a local school, working for NGOs on a local level, money-lending within the community, and renting personal assets, such as car batteries to charge neighbors' phones. Few of the households we sampled have access to formal credit.

The survey (Muth and Helgeson 2011) consisted of 125 questions, asking about the household's socioeconomic circumstances, its attitudes to natural disaster risks, and the courses of action it would take in the event of a disaster. In the latter two cases, it was the stated opinions of the head of the household that were sought. Two small games were integrated into the survey to measure, in an indirect way, the respondents' risk preferences. Such an approach is a hybrid of what is known, in the field of economic valuation, as a stated-preference approach, whereby respondents are directly asked to report their preferences, and a revealed-preference approach, whereby preferences are deduced from real behavior (Pearce et al. 2006). The advantage of the latter is that problems created by the generally hypothetical nature of stated-preference questions, and other aspects of the interview context, can be avoided. However, real behavior is complex and difficult to disentangle into the constructs of interest because in many cases the relevant real behavior simply does not exist or cannot be measured. We make use of the results of one of the games, which we further explain in Appendix 1. Finally, a series of literacy and numeracy questions tailored to a developing-world context were asked in the survey with the results used as a control for other responses.

The survey was administered in the field by the Grameen Foundation's network of community knowledge workers (CKWs). A CKW is a local person who is familiar with the realities of the farmer's daily life, including agricultural practices and typical financial arrangements. A CKW speaks the local language/dialect and lives in-country, often on an income similar to that of the farmers with whom she or he works. One hundred and fifty CKWs in the two regions were equipped with smartphone technology. The survey tool took the form of a software application. Responses were gathered from each survey respondent by a CKW and remotely transmitted to a central database. Before administering the survey, we held two training sessions with CKW in each study region, as well as a pilot study, again in both Kapchorwa and Oyam.

There were a total of 3258 usable responses in the dataset, 1858 were from households in the Kapchorwa region, and 1400 from Oyam. One hundred and nineteen responses were dropped from the dataset ( 53 from the Kapchorwa region and 66 from Oyam), either because they were incomplete and key pieces of information were missing, or because responses were judged by the authors to be implausible and likely the result of mistakes in data entry, misunderstandings between the respondent and the $\mathrm{CKW}$, or similar errors. During the survey process, there was a nonresponse rate of about $6 \%$ reported by the CKWs. The main reason given for nonresponse was that potential respondents were busy farming.

The mean age of the household head was 40.4 years, with a standard deviation of 13. The mean number of household members in addition to the survey respondent was 4.9 (s.d. 2.9). The average land holding was 5.1 acres (s.d. 70.7), but more than $60 \%$ of the sample farmed less than 2 acres of land and nearly all owned the land they farmed. The skew in the distribution of the size of land farmed is thus clear.

It was rare that our households shared land, and only $20 \%$ did so for any part of the growing season. Fifty-two percent of the sample generated more than half of their total household income through farming (Table 1) and $80 \%$ had surplus crops to sell on the market. Table 2 outlines the survey sample's educational attainment in terms of years of schooling.

Table 1. Percentage of household income from farming activities.

\begin{tabular}{lcccc}
\hline \hline Region & \multicolumn{4}{c}{ Percent income from farming } \\
\cline { 2 - 5 } & $0-25 \%$ & $25-50 \%$ & $50-75 \%$ & $75-100 \%$ \\
\hline All & 19.4 & 18.1 & 27.7 & 33.2 \\
Kapchorwa & 20.3 & 19.5 & 26.7 & 32.0 \\
Oyam & 18.1 & 16.3 & 29.1 & 34.9 \\
\hline
\end{tabular}

Table 2. Years of schooling of the household head.

\begin{tabular}{lcccc}
\hline \hline Region & \multicolumn{4}{c}{$\begin{array}{c}\text { Educational level attained by household head (percentage } \\
\text { of sample) }\end{array}$} \\
\cline { 2 - 5 } & $\begin{array}{c}\text { No formal } \\
\text { education }\end{array}$ & $\begin{array}{c}\text { Primary } \\
\text { school }\end{array}$ & $\begin{array}{c}\text { O-level } \\
\text { equivalent }\end{array}$ & $\begin{array}{c}\text { Above O- } \\
\text { level }\end{array}$ \\
\hline All & 18.78 & 45.76 & 26.30 & 9.15 \\
Kapchorwa & 20.61 & 38.37 & 31.16 & 9.85 \\
Oyam & 16.36 & 55.57 & 19.86 & 8.21 \\
\hline
\end{tabular}

The majority of farmers obtained funds in a time of disaster from friends and family, although if the disaster was covariate then this was only of value if the help was obtained from outside the community. As expected, the proportion of those receiving remittances from outside their village was correlated with the percentage of those with close family living outside their village. Looking at the opposite flow, upward of $70 \%$ of the sample sent remittances outside the village on a regular basis, $23 \%$ by means of mobile money.

As mentioned, we used a game, involving coins, to gauge risk aversion in the context of farming. The results were measured in terms of the coefficient of relative risk aversion, the standard measure of risk aversion in economics (Gollier 2001). The results of this game are presented in Table 3 because we will 
later make use of them in our econometric analysis, albeit the interpretation of the variable must be at the ordinal level of measurement.

Table 3. Risk aversion.

\begin{tabular}{lccccc}
\hline \hline Region & \multicolumn{5}{c}{ Coefficient of relative risk aversion (higher means more risk } \\
& \multicolumn{5}{c}{ averse) } \\
\cline { 2 - 6 } & $<0.1$ & $0.1-1.3$ & $1.3-3.2$ & $3.2-5.0$ & $>5.0$ \\
\hline All & 13.96 & 7.61 & 30.73 & 12.32 & 35.38 \\
Kapchorwa & 18.42 & 8.74 & 31.16 & 13.91 & 27.77 \\
Oyam & 7.82 & 6.06 & 30.14 & 10.12 & 45.86 \\
\hline
\end{tabular}

\section{PREVALENCE OF COPING STRATEGIES}

Respondents to our survey were presented with a scenario in which they fall victim to a hypothetical natural disaster, most plausibly a drought or flood, which is covariate, in the sense that all households in the area are affected and thus respondents are told to assume there would be no form of help, e.g., remittances, available from family or friends close by. They were presented with twelve coping strategies and asked to choose as many as they would expect to employ in such a situation. It was possible to choose none. Table 4 lists these coping strategies and the frequency of responses for each strategy across the whole sample, and in Kapchorwa and Oyam regions individually. Our list of coping strategies was initially developed by reviewing the literature. We also conducted background qualitative field interviews in both Kapchorwa and Oyam to check the relevance of our set of strategies to the local context.

Table 4. Coping strategies that would be used after a disaster event.

\begin{tabular}{lccc}
\hline \hline \multirow{2}{*}{ Coping Strategy } & \multicolumn{2}{c}{ Frequency (percentage of total) } \\
\cline { 2 - 4 } & Total Sample & Kapchorwa & Oyam \\
\hline Reduction of food intake & $738(23)$ & $419(23)$ & $323(23)$ \\
Borrow food & $624(19)$ & $379(20)$ & $251(18)$ \\
Reducing expenditures & $1250(38)$ & $697(38)$ & $558(40)$ \\
Sell livestock & $2196(68)$ & $1290(70)$ & $913(65)$ \\
Begging & $327(10)$ & $179(10)$ & $153(11)$ \\
Sell household items & $336(10)$ & $182(10)$ & $157(11)$ \\
Sell land or home & $95(3)$ & $40(2)$ & $59(4)$ \\
Take children out of & $67(2)$ & $33(2)$ & $41(3)$ \\
school & & & \\
Send children to live & $38(1)$ & $29(2)$ & $16(1)$ \\
elsewhere & & & \\
Migrate & $44(1)$ & $37(2)$ & $10(1)$ \\
Change profession & $294(9)$ & $157(9)$ & $138(10)$ \\
Send children to work & $178(6)$ & $81(4)$ & $99(7)$ \\
\hline
\end{tabular}

The results across the two regions were very similar. Thus, we can say with some confidence that conditional on the scenario we presented region-specific factors were unimportant in determining the frequency of uptake of coping strategies.
What was particularly interesting about the results was the frequency with which the sale of livestock was chosen. It was by a large margin the most frequently chosen coping strategy, i.e., $68 \%$ of the pooled sample would use it, compared to $38 \%$ for the next most popular strategy, reducing expenditures. To some extent, this was to be expected, because livestock is a commonly held asset among sampled households, i.e., 91\% of households reported owning livestock. In addition, the sale of livestock may not undermine the household's productive base as much as some other strategies, such as selling land or one's home, or disrupting the children's education, especially in conditions where the livestock may not be able to graze well for some time. This high frequency of livestock ownership and willingness to cope via livestock sale supports the claim that farmers in the rural developing world use livestock as a form of liquid savings (Dercon 1998, Kinsey et al. 1998). We cannot make that claim definitively, however, because our survey response categories did not distinguish between the sale of surplus livestock that may have been accumulated during times of relative plenty precisely for insurance against natural disasters, and the sale of livestock required for subsistence.

On the other hand, it was surprising that strategies involving reducing current consumption or augmenting it through other means were not chosen more frequently. This runs somewhat counter to the literature on coping strategies, which suggests they are chosen in sequence such that the disposal of productive assets is resisted until other possibilities have been exhausted (Corbett 1988). These include the reduction of food intake, chosen by $23 \%$ of the pooled sample, borrowing food (19\%), reducing expenditures $(38 \%)$, begging $(10 \%)$, and perhaps some forms of migration, e.g., temporarily for work (only 1\%).

It might be argued that food intake and expenditures cannot be reduced because households are already at subsistence level, and further reductions in consumption would present potentially severe consequences for lives. There may certainly be some truth to this, especially if the disaster is severe, but $81 \%$ of households in our sample were able to sell surplus crops on the market under normal circumstances, i.e., they were above subsistence prior to the shock. Moreover, this does not explain the reluctance to beg and borrow. It remains striking that sale of livestock was reported so much more frequently than reducing consumption, or augmenting it through borrowing or begging.

More consistent with the literature is the finding that coping strategies that more unambiguously erode the household's stock of productive assets, were seldom chosen. Among these were strategies involving disrupting the children's education, i.e., taking children out of school, sending children to live elsewhere, and sending children to work, suggests that, across the board, households do indeed take education seriously and 
Table 5. Principal components analysis loadings.

\begin{tabular}{|c|c|c|c|c|}
\hline Component & 1 & 2 & 3 & 4 \\
\hline Sell land or home & 0.141105 & 0.37362 & -0.066 & 0.437837 \\
\hline Sell livestock & -0.15134 & 0.22887 & 0.621184 & 0.229587 \\
\hline Change profession & 0.048482 & 0.008033 & -0.69758 & 0.021163 \\
\hline Beg & 0.254222 & 0.212041 & -0.12513 & -0.3422 \\
\hline Take children out of school & 0.270276 & 0.348158 & -0.01925 & 0.369079 \\
\hline Send children to live elsewhere & 0.230579 & 0.413378 & 0.101 & -0.27516 \\
\hline Sell household items & 0.326232 & 0.190426 & -0.06193 & 0.041663 \\
\hline Migrate & 0.232515 & 0.245374 & 0.136839 & -0.53162 \\
\hline Eat less & 0.42126 & -0.39377 & 0.127547 & 0.039524 \\
\hline Borrow food & 0.440882 & -0.09887 & 0.122783 & -0.03415 \\
\hline Send children to work & 0.321157 & -0.02363 & -0.10315 & 0.371403 \\
\hline Reduce Expenditures & 0.358498 & -0.45721 & 0.17997 & 0.032845 \\
\hline$\%$ Variance Accounted for by Component & 17.98 & 11.26 & 9.82 & 9.28 \\
\hline
\end{tabular}

treat it as a long-term investment, as theories of household capital formation would suggest (Barham et al. 1995).

Because households could choose several strategies, as they can in a real disaster situation, it is of further interest to examine the response data for frequently chosen combinations. We employed a principal components analysis (PCA) to do this. PCA is a commonly used method in exploratory data analysis for identifying, among other things, how variables cluster in a dataset. We wanted to identify whether there were clusters of coping strategies that were frequently chosen together and, if so, what strategies comprised these clusters. One can thus think of a component as an overarching strategy choice, which is realized through choosing specific coping strategies.

Figure 2 displays the results of the PCA in terms of a scree plot (Cattell 1966), which plots the principal components of the dataset against their eigenvalues, a measure of the amount of variance in the dataset explained by each component. Highly clustered datasets yield scree plots in which the eigenvalues drop off very steeply from the first component, quickly flattening out. In addition, Kaiser (1960) proposed a well-known criterion for the interpretation of PCA results, such that only those components whose eigenvalues are greater than one are retained.

What is striking about Figure 2 is how gently the scree plot falls away, especially from the second component onward. The eigenvalue of the first component is also relatively low because it is not unusual to see eigenvalues of well over five in highly clustered datasets. Thus, there appears to be relatively little clustering of coping strategies in the survey data. This hints at a heterogeneous set of strategy combinations chosen by the sample households, and/or at few households choosing combinations at all. Were it the case that certain combinations of strategies were frequently chosen, we would have expected to see the relevant components explain more of the sample variance.
Fig. 2. Scree plot of eigenvalues for principal components analysis of coping strategies.

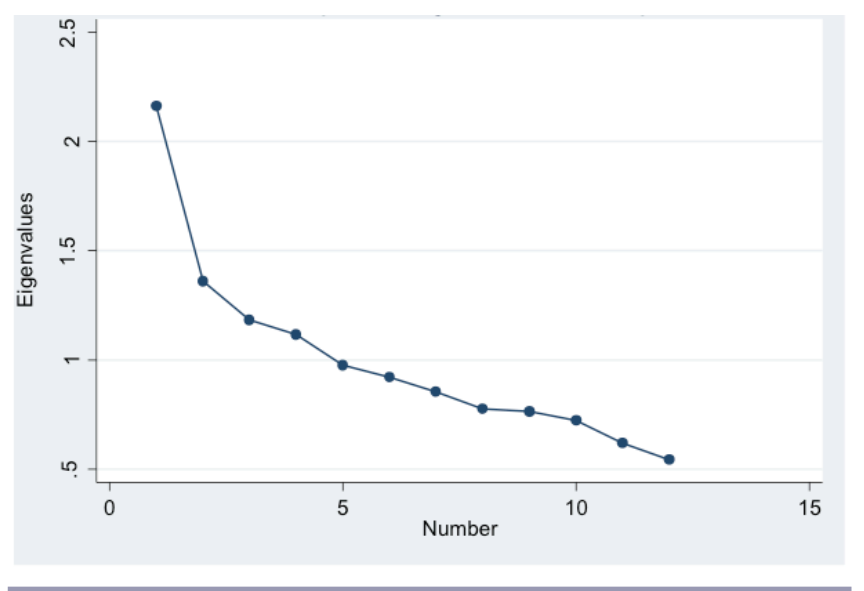

Table 5 presents the component loadings, whereby a loading is the correlation between the variable and the component on the first four components whose eigenvalues are greater than one. The higher the loading, the higher the association between a strategy and the overall component, i.e., the overarching strategy. Consistent with the lack of clustering indicated by Figure 2, the loadings are generally small. There is some weak evidence that strategies involving reducing current consumption are sometimes chosen together because the first component has higher loadings on borrowing food, eating less, and reducing expenditure. The second component has higher loadings on sending children to live elsewhere and taking children out of school, which are similar strategies, seldom chosen overall (see Table 4). Perhaps the strongest result is for the third component, which has a very strong loading on selling livestock, but very weak loadings on all other strategies, indicating that this most popular strategy tends to be chosen in isolation. 
Besides the lack of variance accounted for by the principal components and what this indicates about the survey responses, one of the main conclusions we can draw from the PCA is that the component structure is rather at odds with the popular theory that strategies are chosen in typical sequences (Corbett 1988). Were that the case, the sequences should have been evident in the results.

\section{DETERMINANTS OF ASSET LIQUIDATION}

Of the 12 coping strategies presented to respondents, 6 could fall into the category of capital disinvestment, i.e., sell livestock, sell household items, sell land or home, take children out of school, send children to live elsewhere, and send children to work. Within this subset, by far the most readily adopted would be the sale of livestock, with $68 \%$ of the sample willing to do so. Therefore, even though it is unclear to what extent sale of livestock affects the household's future prospects, on weight of numbers alone, it is of interest to analyze what determines the choice of this strategy, either in isolation or in combination with any other strategies. To do this we constructed a binomial variable, LivestockLiq, which took the value of 1 for those households indicating a willingness to utilize the coping strategy of livestock sales. Clearly, only households that own livestock can sell it, so we accounted for this by restricting the sample to livestockowning households, reducing the sample by only 290 households.

We also focused on the choice of disinvestment strategies that would take children out of the educational system. Given the rising importance of human-capital formation to development, and notwithstanding the continuing importance of practical learning-by-doing in the labor markets of less-developed economies, these strategies can be particularly important in affecting long-run vulnerability. We developed the binomial variable, AssetLiqChild, which took the value of 1 for those households indicating willingness to take children out of school, send children to live elsewhere, and/or send children to work.

These two variables, LivestockLiq and AssetLiqChild, were used as dependent variables in a regression analysis of our survey data to shed light on which socioeconomic and attitudinal factors determined their uptake by households. Note that because of the rather weak clustering of strategies, we did not take forward the principal components into this analysis.

Research on household vulnerability to natural hazards has previously emphasized the importance of capital assets (Wisner et al. 2004, Carter and Barrett 2006), so we included measures of (1) the household's built and financial capital and (2) its human capital. Because neither of these forms of capital is directly observed, we used proxies for them based on relevant literature and what our survey made available.
For built/financial capital, we used the acreage of land owned by a household as our proxy measure (Acres). Previous literature has suggested that there is a strong relationship between access to land and household income, certainly in eastern and southern Africa (Jayne et al. 2003). Human capital is straightforwardly captured via the ordinal-level variable education, which summarizes the respondent's years of schooling. The data for this variable, in Table 2, shows that the majority of respondents $(64 \%)$ leave formal education at the end of elementary/primary school at the latest, a further $26 \%$ of respondents leave school at the ordinary level, i.e., Olevel, and only $9 \%$ of respondents remain in school thereafter to complete advanced-level secondary education. Natural capital stocks are stressed in the literature, but we excluded them in this study because it was assumed that environmental conditions were the same in a given period for all households sampled. Social capital is also stressed in the literature, but social capital is notoriously hard to measure, and in our scenario it is social capital that exists beyond the local level that is of interest because the natural disaster scenario is covariate. We included one explanatory variable that partially captures social capital beyond the local level.

We included several other explanatory variables relating to the household's wealth and income. None of these were highly correlated with the others, and each promised to control for a rather different effect, so we included them in our models.

First, we included the share of household income from farming (IShare). This was an ordinal-level variable ranging from 0 (0-25\%) to $3(75-100 \%)$, which mapped to intervals that respondents could choose in the survey. Two households with the same income, and perhaps also wealth, but with differing degrees of dependence on farming for income, might be expected to rely to a different extent on livestock sale in the event of a drought or flood; for example, more diversified households may be less reliant on selling livestock because they have other coping strategies within their feasible set.

Second, we included a dummy variable indicating whether a household was engaged in subsistence farming or whether it was able to sell surplus crops to the market (Surplus). This may, for example, affect whether a household has a reduction in food intake or expenditure within its feasible set. It may also affect the relative impact on a household of a disaster that affects crop yields. Note that for interpretation of the results, the coding of this dummy variable was 0 for a surplus and 1 for no surplus.

Third, we specified the dummy variable (FamRem), which indicated whether the household was a net recipient of remittances from outside of its village, or a net provider beyond the village. This was first and foremost an indicator of the household's financial position, i.e., we assumed net providers were in a stronger position, all else being equal, but because remittances also depend on social capital, it can be seen to 
partially capture super-local social capital stocks as well. About $47 \%$ of households received more in remittances from outside the village than they provided, although $34 \%$ were net providers. The remainder neither sent nor received remittances.

That there could be connections between the choice of coping strategy and attitudes to risk, especially those held by the head of the household, is intuitive. To gauge the effect of risk perceptions, we included the outcome of our coin game for each respondent (CoinRisk). The coin game provided us with a measure of household risk aversion, specifically as it applies to agricultural planning. In this model, we used an ordinal variable to indicate if a respondent was relatively more risk averse. The higher the variable value for a given household, the more risk averse it was. We also controlled for the age of the household head via the variable Age, and we controlled for the size of the household (FamSize). A particular concern in any regression model is bias resulting from unobserved variation. This is more difficult to counter in cross-sections than in panel datasets, but we included two variables to deal with it. Possible regional differences were incorporated in the model by specifying a region-level dummy variable (Region) that took on different values depending on whether the respondent was located in Oyam or Kapchorwa. More importantly, we exploited detailed local data on where the responses were garnered to specify 34 dummy variables at the sub-county level. The estimation technique is probit. Table 6 summarizes the regressors.

Table 6. Explanatory variables of differential vulnerability.

\begin{tabular}{lcc}
\hline \hline Variable & Name & $\begin{array}{c}\text { Scale of } \\
\text { measurement }\end{array}$ \\
\hline Region & Region & Categorical \\
Educational status & Education & Ordinal \\
Acres owned & Acres & Ordinal \\
Age & Age & Continuous \\
Family size & FamSize & Continuous \\
Income share from activities outside & IShare & Ordinal \\
farming & & Categorical \\
Surplus crop sold on the market & Surplus & Ordinal \\
Risk aversion & CoinRisk & Categorical \\
Remittances & FamRem &
\end{tabular}

Table 7 (column i) presents the estimated probit model for willingness to sell livestock. It shows good explanatory power overall. A number of key explanatory variables were individually significant in the model. Of these, IShare and Surplus were significant at better than the $1 \%$ level, the former positive, the latter negative. In particular, households with a higher share of income from farming were more likely to sell livestock after a natural disaster, as were those households that grow surplus crops to sell on the market. In both cases, the most likely explanation is that the variable reflects vulnerability to natural disasters and that greater vulnerability leads to a greater reliance on the sale of livestock to cope. IShare was indicative of the diversification of household employment, which has been shown to be associated with lower levels of vulnerability (Wisner et al. 1994). Furthermore, diversification has been argued to act as a safety valve for the rural poor by providing a broader set of feasible coping strategies from which to choose (Ellis 2000). Households that have surplus output to sell on the market (Surplus) lose not only their own source of food when a natural disaster wipes out crops, but they also lose potential income from market sales, burdening them with a greater need to cope overall. It might be objected that households selling surplus crops on the market are better off and therefore less vulnerable to natural disasters because their farms are more productive, but recall that we control in various ways for household income and wealth.

Table 7. Probit models of the determinants of strategies to (i) sell livestock and (ii) taking children out of education.

\begin{tabular}{lcc}
\hline \hline Variable & (i) LivestockLiq & (ii) AssetLiqChild \\
\hline Region & -6.52 & -3.14 \\
Education & 0.03 & $-0.16 * * *$ \\
Acres & -0.001 & -0.000 \\
Age & $0.004 * * 25 * 6$ & $0.006 * *$ \\
FamSize & $0.025^{*}$ & $0.042 * * *$ \\
IShare & $0.098 * * *$ & -0.009 \\
Surplus & $-0.314 * * * 16$ & 0.016 \\
CoinRisk & $-0.161 * *$ & 0.170 \\
FamRem & 0.050 & -0.005 \\
Number of Ob & 2788 & 2935 \\
Log likelihood & -1471.59 & -726.440 \\
Pseudo R & 0.134 & 0.166 \\
\hline
\end{tabular}

FamSize and CoinRisk had significant positive effects on willingness to sell livestock, albeit only at the 5\% level. The greater the family size, the more likely it is that the household will sell livestock to cope, which could again reflect a positive association between family size and vulnerability, i.e., the larger the family the more mouths there are to feed. Together with the significant coefficients on IShare and Surplus, the picture is thus building that the sale of livestock is a strategy commonly turned to by households more vulnerable overall to natural disasters. This picture is in turn consistent with the notion that livestock is held as a liquid asset to form a first line of defense in coping with such shocks, although it is also consistent with the notion that more vulnerable households cannot cope by reducing consumption alone, or by using other strategies that avoid disinvestment, i.e., livestock is only sold once the returns from other strategies have been exhausted. Yet we know that such strategies are used less frequently, and we did not find evidence that they were employed in combination with selling livestock.

The positive coefficient on CoinRisk indicated that, the more the head of the household was risk averse, the less likely it 
was that livestock was sold as a means to cope. This could reflect a number of considerations because the dynamic relationship between coping strategies and income risk for particular households is extremely difficult to know. It could also reflect a correlation between CoinRisk and income/ vulnerability because it is widely thought that relative risk aversion decreases with household income (see Rosenzweig and Binswanger 1993 for classic evidence on farmers' risk aversion).

Age was significant at the $10 \%$ level and positive, indicating that households in which the household head was relatively older were more likely to sell livestock as a means of coping. It is probable that age encompasses an underlying effect not accounted for directly in our model. By way of one possible explanation, in many rural societies age correlates with changes in the role played within the wider community (Lipton and Maxwell 1992). The older the household head, the higher the cost to his reputation from borrowing or begging, for example. With increasing age may also come reduced mobility, ruling out coping strategies involving migration, for instance. Neither our financial-capital nor human-capital proxies were significant in this model.

The probit model with the dependent variable AssetLiqChild is shown in Table 7 column (ii). As mentioned previously, this type of coping strategy unambiguously reduces the household's investment in capital (human capital) that would likely reap returns in the future. The estimated model shows good explanatory power overall. Education was significant at the $1 \%$ level and negative, indicating that, the higher the educational attainment of the household head, the less likely they were to risk compromising their children's educational attainment. It may well be that those with higher educational attainment placed more value on investment in human capital per se because, within our sample, there was no significant correlation between education and built/financial capital wealth.

By contrast, FamSize was significant at the $1 \%$ level and positive, indicating a higher propensity to disrupt the children's education after a natural disaster when the family size is greater. This is intuitive because households that have more people to care for are more likely to take up coping strategies that may endanger future prospects, but stabilize household prospects in the immediate term. With increased family size, in particular increased numbers of children, we can also hypothesize an effect at the margin, whereby the cost to future prospects of having one less child in formal education is lower. There was a weak, i.e., significant at the $10 \%$ level, positive association between Age and AssetLiqChild, which may again reflect factors linked with age.

\section{DISCUSSION}

Our survey results suggest that the sale of livestock is by far the most frequently chosen coping strategy after a weather disaster. This runs counter to some previous studies indicating that the sale of livestock plays a minor role in coping with extreme weather (Fafchamps and Gavian 1996, Kazianga and Udry 2006), and to the thrust of the literature on choosing coping strategies in sequence (Corbett 1988), such that a reduction in current consumption is always attempted prior to liquidating any assets. We found that strategies involving reducing current consumption or augmenting it by borrowing/ begging would be used fairly seldom. Conversely our results support the argument that livestock is held as a form of liquid savings, one possible use of which is to recover from a shock (Dercon 1998).

Our findings reveal a fairly rich set of determinants of different subsets of coping strategies. We chose to focus on drivers of the choice to cope via the sale of livestock, given its prevalence, and the reduction of children's education, given its potential importance. Our findings point out the impact of initial vulnerability on the propensity to disinvest, where initial vulnerability is represented by a lack of income diversification, a large family size, and in the case of selling livestock, whether surplus crops are sold on the market, and hence, how much of a shock the weather event is to household income. However, our findings also point out attitudinal and social factors (thus consistent with Anderson and Woodrow 1998, Eade 1998), notably the effect of educational attainment on educational aspirations for children, attitude to risk, and albeit weakly, age.

There are some limitations to our study, chiefly that our survey questions, being hypothetical in nature, could yield answers affected by various forms of bias. However, the fact that the survey was administered by local CKWs, who had a preexisting relationship with the respondents, built on trust, helped to combat this issue. Also, in the areas researched, large covariate weather shocks, i.e., involving loss of at least half a crop, occurred at least once every four years, so respondents were familiar with the issues in question. Furthermore, in neither region is there formalized agricultural insurance, which also serves to make the scenario realistic.

Though our regression models have good explanatory power, the issue of endogeneity, principally through omitted variables, is one that we need to be aware of. We account for this as best we can by (1) specifying a rich set of regressors, none of which is highly correlated with other regressors, and (2) by including dummy variables at the subcounty and regional levels to account for unobserved variations.

Responses to this article can be read online at: http://www.ecologyandsociety.org/issues/responses. php/5390 


\section{Acknowledgments:}

We would like to thank seminar participants at LSE, the editors of the journal and of this special issue, and two anonymous referees for comments on the research. The financial support of the Grantham Foundation for the Protection of the Environment is gratefully acknowledged, as is that of the Centre for Climate Change Economics and Policy, which is funded by the UK Economic and Social Research Council (ESRC) and Munich Re. We would also like to thank the Grameen Foundation for financial and logistical support, especially allowing us to use the Community Knowledge Worker network.

\section{LITERATURE CITED}

Adger, W. N., and A. Winkels. 2007. Vulnerability, poverty, and sustainable well-being. Pages 189-204 in G. Atkinson, S. Dietz, and E. Neumayer, editors. Handbook of sustainable development. Edward Elgar, Gloucester, UK.

Anderson, M. B., and P. J. Woodrow. 1998. Rising from the ashes: development strategies in times of disaster. Lynne Rienner, Boulder, Colorado, USA.

Banerjee, A. V. 2000. The two poverties. Nordic Journal of Political Economy 26:129-141. [online] URL: http://www. nopecjournal.org/NOPEC 2000 a07.pdf

Barham, V., R. Boadway, M. Marchand, and P. Pestieau. 1995. Education and the poverty trap. European Economic Review 39:1257-1275. http://dx.doi.org/10.1016/0014-2921(94)00040-7

Barrett, C. B., M. R. Carter, and P. D. Little, editors. 2006. Understanding and reducing persistent poverty in Africa. Special Issue of Journal of Development Studies 42(2).

Blumenstock, J. E., M. Fafchamps, and N. Eagle. 2011. Risk and reciprocity over the mobile phone network: evidence from Rwanda. CSAE Working Paper WPS/2011-19, Centre for the Study of African Economies, Oxford, UK. http://dx.doi. org/10.2139/ssrn.1958042

Boko, M., I. Niang, A. Nyong, C. Vogel, A. Githeko, M. Medany, B. Osman-Elasha, R. Tabo, and P. Yanda. 2007. Africa. Pages 433-467 in M. L. Parry, O. F. Canziani, J. P. Palutikof, P. J. van der Linden, and C. E. Hanson, editors. Climate change 2007: impacts, adaptation and vulnerability. Contribution of Working Group II to the Fourth Assessment report of the Intergovernmental Panel on Climate Change. Cambridge, Cambridge University Press, UK. [online] URL: http://www.ipcc.ch/publications_and_data/ar4/wg2/en/ch9.html

Carter, M. R., and C. B. Barrett. 2006. The economics of poverty traps and persistent poverty: an asset-based approach. Journal of Development Studies 42:178-199. http://dx.doi. org/10.1080/00220380500405261
Carter, M. R., P. D. Little, T. Mogues, and W. Negatu. 2007. Poverty traps and natural disasters in Ethiopia and Honduras. World Development 35:835-856. http://dx.doi.org/10.1016/j. worlddev.2006.09.010

Cattell, R. B. 1966. The meaning and strategic use of factor analysis. Pages 174-243 in R. B. Cattell, editor. Handbook of multivariate experimental psychology. Rand McNally, Chicago, Illinois, USA.

Corbett, J. 1988. Famine and household coping strategies. World Development 16(9):1099-1112. http://dx.doi. org/10.1016/0305-750X(88)90112-X

Dercon, S. 1998. Wealth, risk and activity choice: cattle in western Tanzania. Journal of Development Economics 55 (1):1-42. http://dx.doi.org/10.1016/S0304-3878(97)00054-0

Duryea, S. 1998. Children's advancement through school in Brazil: the role of transitory shocks to household income. Working Paper 376, Office of the Chief Economist of the InterAmerican Development Bank, Washington, D.C., USA. [online] URL: http://papers.ssrn.com/sol3/papers.cfm? abstract $\mathrm{id}=1816004$

Eade, D. 1998. Capacity building: an approach to peoplecentered development. Oxfam, Oxford, UK.

Ellis, F. 2000. Rural livelihoods and diversity in developing countries. Oxford University Press, Oxford, UK.

Ellis, F., and N. Mdoe. 2003. Livelihoods and rural poverty reduction in Tanzania. World Development 31(8):1367-1384. http://dx.doi.org/10.1016/S0305-750X(03)00100-1

Fafchamps, M., and S. Gavian. 1996. The spatial integration of livestock markets in Niger. Journal of African Economies 5(3):366-405. http://dx.doi.org/10.1093/oxfordjournals.jae. $\underline{\mathrm{a} 020912}$

Flug, K., A. Spilimbergo, and E. Wachtenheim. 1998. Investment in education: do economic volatility and credit constraints matter? Journal of Development Economics 55:465-481. http://dx.doi.org/10.1016/S0304-3878(98)00045-5

Galor, O. 2011. Unified growth theory. MIT Press, Cambridge, Massachusetts, USA.

Gollier, C. 2001. The economics of risk and time. MIT Press, Cambridge, Massachusetts, USA.

International Panel on Climate Change (IPCC). 2007. Summary for policymakers. Pages 48-54 in S. Solomon, D. Qin, M. Manning, Z. Chen, M. Marquis, K. B. Averyt, M. Tignor, and H. L. Miller, editors. Climate Change 2007: the physical science basis. Contribution of Working Group I to the Fourth Assessment report of the Intergovernmental Panel on Climate Change. Cambridge University Press, Cambridge, UK. http://dx.doi.org/10.1017/CBO9780511546013.003 
Jack, W., and T. Suri. 2011. Mobile money: the economics of m-pesa. National Bureau of Economic Research (NBER) Working Paper 16721, NBER, Cambridge, Massachusetts, USA.

Jacoby, H. G., and E. Skoufias. 1997. Risk, financial markets, and human capital in a developing country. Review of Economic Studies 64(3):311-335. http://dx.doi.org/10.2307/2971716

Jayne, T. S., T. Yamano, M. T. Weber, D. Tschirley, R. Benfica, A. Chapoto, and B. Zulu. 2003. Smallholder income and land distribution in Africa: implications for poverty reduction strategies. Food Policy 28(3):253-275. http://dx.doi. org/10.1016/S0306-9192(03)00046-0

Kaiser, H. F. 1960. The application of electronic computers to factor analysis. Educational and Psychological Measurement 20:141-151.

Kazianga, H., and C. Udry. 2006. Consumption smoothing? Livestock, insurance and drought in rural Burkina Faso. Journal of Development Economics 79:413-446. http://dx.doi. org/10.1016/j.jdeveco.2006.01.011

Kinsey, B., K. Burger, and J. W. Gunning. 1998. Coping with drought in Zimbabwe: survey evidence on responses of rural households to risk. World Development 26(1):89-110. http:// dx.doi.org/10.1016/S0305-750X(97)00124-1

Lipton, M., and S. Maxwell. 1992. The new poverty agenda: an overview. Discussion Paper No. 306, Institute of Development Studies, University of Sussex, Brighton, UK.

Mechler, R. 2004. Natural disaster risk management and financing disaster losses in developing countries. Verlag Versicherungswissenschaft, Karlsruhe, Germany.

Muth, K. T., and J. F. Helgeson. 2011. Stochastic environments as measurement tools: a new approach. Journal of Applied Economy 5:13-47. [online] URL: http://www2.lse. ac.uk/GranthamInstitute/publications/research-articles/Docs/ stochastic-environment-measurement-tools.pdf

Pearce, D. W., G. Atkinson, and S. Mourato. 2006. Costbenefit analysis and the environment. Organisation for Economic Co-operation and Development (OECD), Paris, France.

Ravallion, M., and S. Chen. 1997. What can new survey data tell us about recent changes in distribution and poverty? World Bank Economic Review 11(2):357-382. http://dx.doi. org/10.1093/wber/11.2.357

Reardon, T., and S. A. Vosti. 1995. Links between rural poverty and the environment in developing countries: asset categories and investment poverty. World Development 23 (9):1495-1506. http://dx.doi.org/10.1016/0305-750X(95)00061G
Rosenzweig, M. R., and H. P. Binswanger. 1993. Weather, risk, and the composition and profitability of agricultural investments. Economic Journal 103:56-78. http://dx.doi. org $/ 10.2307 / 2234337$

Rosenzweig, M. R., and O. Stark. 1989. Consumption smoothing, migration, and marriage: evidence from rural India. Journal of Political Economy 97(4):905-926. http://dx. doi.org/10.1086/261633

Skoufias, E., and S. W. Parker. 2002. Labor market shocks and their impacts on work and schooling: evidence from urban Mexico. IFPRI-FCND Discussion Paper 129, International Food Policy Research Institute, Washington, D.C., USA. [online] URL: http://www.ifpri.cgiar.org/sites/default/files/ publications/fcndp129.pdf

Stern, N. 2007. The economics of climate change: the stern review. Cambridge University Press, Cambridge, UK.

Wisner, B., P. Blaikie, T. Cannon, and I. Davis. 2004. At risk: natural hazards, people's vulnerability and disasters. Routledge, Oxford, UK. 
Appendix 1. The coin game.

The coin game is a way to quickly measure the risk aversion of a single subject through binary-choice iterations. The game is designed in a triple-bounded dichotomous-choice structure. The subject is given two coins and told each coin represents a crop he could choose to grow in the coming season. One flip of the coin will decide the size of the harvest his crop yields. The participant is allowed to examine and handle the coins, which are metal tokens (see Figure A.1), and is then asked to choose which crop he will plant (dichotomous choice). One coin offers a yield of 5 on either side, thus being risk-free, while the other coin offers yields of 9 on one side and 3 on the reverse, thus involving risk. For consistency, in describing administrations of the game, the former coin is referred to as 'Alpha', while the latter is called 'Beta'. The yields are expressed in arbitrary units, with icons representing crops to minimize any cultural or linguistic skew in the results.

Figure A.1. The coins.
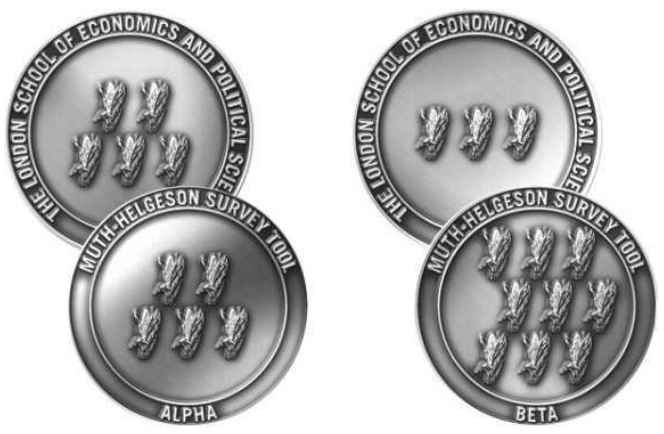

The Choices Offered in Round One of the Coin Game

After the subject chooses between Alpha and Beta in the first round, he is provided in a second round with a choice of two new coins. The choice of coins depends on the coin chosen in the first round, according to the decision tree in Figure A.2. It is possible to go through three rounds (triple-bounded), as illustrated by the shaded pathway in the figure.

Figure A.2. Constant-relative-risk-aversion decision tree.

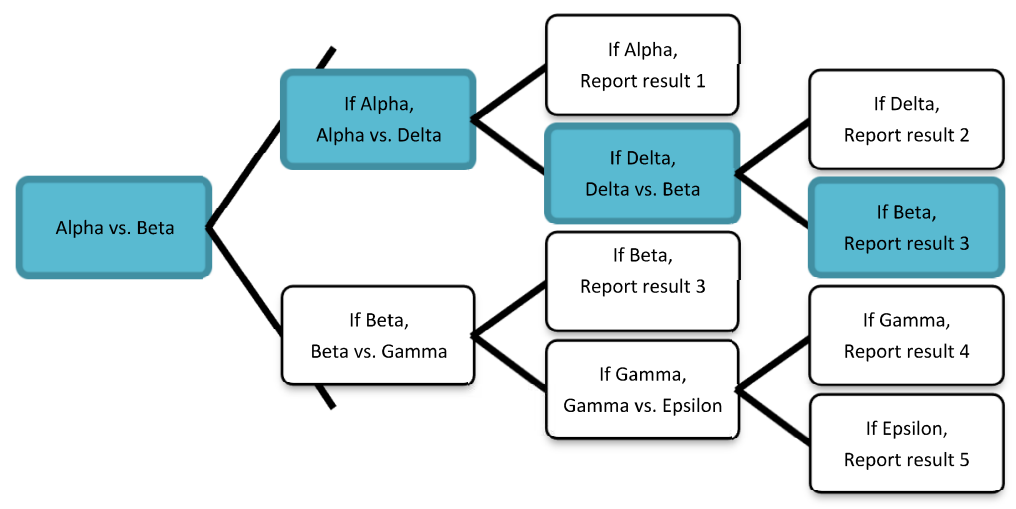

Note that maize was chosen as the crop to display on the coins, as it is familiar to nearly all farmers in Uganda. 
The game itself is a version of a classic risk-aversion classification exercise. To analyze the game output, we use the framework of constant relative risk aversion. Under constant relative risk aversion, the utility of consumption $u(c)$ is given by the following function:

$$
u(c)=\frac{c^{1-\sigma}}{1-\sigma}
$$

where $\sigma$ is the coefficient of relative risk aversion, a parameter controlling the curvature of the utility function, which measures risk aversion.

Where the player chooses the 9:3 coin (Alpha) rather than the 5:5 coin (Beta) in the first round of the game, his choice is mathematically equivalent to an inequality between probabilities where the participant prefers one probability to the other. The choice of the 9:3 coin can be represented by:

$$
5^{1-\sigma}=\frac{1}{2}\left(9^{1-\sigma}+3^{1-\sigma}\right) \rightarrow \sigma_{9: 3}
$$

As the context of each decision is a choice between two coins and the probabilities of any given outcome at any given time are equal, this follows for all other values in the opportunity set, e.g.:

and

$$
\therefore 5^{1-\sigma}=\frac{1}{2}\left(8^{1-\sigma}+4^{1-\sigma}\right) \rightarrow \sigma_{8: 4}
$$

$$
\therefore 5^{1-\sigma}=\frac{1}{2}\left(10^{1-\sigma}+2^{1-\sigma}\right) \rightarrow \sigma_{10: 2}
$$

This method allows the player to be quickly categorized according to the variance he will tolerate with two choices at a mutual probability of 0.5 . The coins represent variances of the following values (each of which represents a comparison of a coin's two sides expressed as a fraction): $1,1 / 2,1 / 3,1 / 5,1 / 11$.

Hence, the participants are classified into five categories of risk aversion. 